\title{
Decreased risk of breast cancer associated with oral bisphosphonate therapy
}

This article was published in the following Dove Press journal:

Breast Cancer:Targets and Therapy

22 May 2012

Number of times this article has been viewed

\author{
Aju Mathew' \\ Adam Brufsky ${ }^{2}$ \\ 'Department of Internal Medicine, \\ University of Pittsburgh Medical \\ Center, ${ }^{2}$ Division of Hematology/ \\ Oncology, Magee-Womens Hospital, \\ University of Pittsburgh Cancer \\ Institute, Pittsburgh, PA, USA
}

\begin{abstract}
Preclinical studies and adjuvant trials using bisphosphonates have found them to have an antitumor effect. Although major advances have been made in chemoprevention strategies with selective estrogen receptor modulators and aromatase inhibitors, their use has been fraught with significant adverse effects such as venous thromboembolic events and an increased risk for endometrial cancer. In this context, several recent observational studies have investigated a chemoprevention role for oral bisphosphonates in decreasing risk for breast cancer. This review will aim to summarize these studies and present a critical evaluation of the association between oral bisphosphonate use and breast cancer risk reduction.
\end{abstract}

Keywords: incidence, risk reduction, chemoprophylaxis, alendronate, zoledronate

\section{Introduction}

Breast cancer is the most common cancer diagnosis in women. It is estimated that there will be more than 220,000 new cases of breast cancer in $2012 .{ }^{1}$ It is also expected to be the leading cause of cancer death in women, with nearly 40,000 deaths predicted this year. ${ }^{1}$ There have been many advances in chemoprevention strategies targeting women with high risk for breast cancer involving two categories of drugs - selective estrogen receptor modulators (tamoxifen and raloxifene) and aromatase inhibitors.

\section{Current chemoprevention strategies}

Numerous randomized controlled trials have established the role of tamoxifen, a selective estrogen receptor modulator, in breast cancer prevention. ${ }^{2-4}$ It was found that the use of tamoxifen for 5 years decreased the risk of invasive breast cancer by about $50 \%$ when compared to placebo. ${ }^{3}$ However, the significant adverse effects for thromboembolic events and the increased risk for endometrial cancer in those treated with tamoxifen led to further trials with another selective estrogen receptor modulator, raloxifene..$^{2-5}$ A trial of raloxifene found a 38\% risk reduction for invasive breast cancer with the drug when compared to placebo. ${ }^{6}$ There were also significantly fewer adverse effects such as thromboembolic events, uterine hyperplasia, and endometrial cancer with raloxifene when compared to tamoxifen. ${ }^{6,7}$ Both these drugs were approved for breast cancer risk reduction by the US Food and Drug Administration. However, in clinical practice, both drugs are rarely used for the prevention of invasive breast cancer mainly due to persisting concerns about adverse effects. ${ }^{8}$

The second category of drugs that has been studied in breast cancer chemoprevention is aromatase inhibitors. Several adjuvant trials with aromatase inhibitors found
Correspondence: Aju Mathew

200 Lothrop Street, N7I 3, Pittsburgh

PA I5213, USA

Tel + I 412958 I304

Fax + I 4I264|646I

Email mathewa@upmc.edu 
a significant risk reduction for contralateral breast cancers compared to tamoxifen use. Furthermore, the MAP.3 breast cancer prevention trial in postmenopausal women comparing exemestane with placebo found a moderately decreased risk for breast cancer with the drug use. ${ }^{9}$ After a median follow-up of about 3 years, the MAP. 3 trial found a $65 \%$ risk reduction in the annual incidence of invasive breast cancer when compared to placebo. Most notably, there were no significant differences between the two groups in the incidence of skeletal fractures, cardiovascular events, or cancers. Another aromatase inhibitor, anastrozole, is currently being studied for breast cancer prevention in postmenopausal women (IBIS-II trial). ${ }^{10}$ It should however, be noted that selective estrogen receptor modulators are still the drug of choice for breast cancer prevention in premenopausal women.

\section{Bisphosphonates as chemoprevention agents in breast cancer}

Bisphosphonates are another category of drugs that have been explored in the context of the chemoprevention of breast cancer. This review will focus on the role of oral bisphosphonate therapy in decreasing the risk of breast cancer.

\section{Mechanism of action}

Bisphosphonates are analogues of pyrophosphate that strongly bind to the hydroxyapatite crystals of bone. ${ }^{11}$ Osteoclasts induce changes in $\mathrm{pH}$ in the bone surface during the bone resorptive process, which result in the release of bisphosphonates from the bone surface. The bisphosphonates are then internalized by osteoclasts through endocytosis. In return, the bisphosphonates produce cellular level changes leading to an inhibitory effect on the osteoclasts. ${ }^{12}$ There are essentially two kinds of bisphosphonates - non-nitrogen containing bisphosphonates such as clodronate and etidronate and the nitrogen-containing bisphosphonates (aminobisphosphonates) such as alendronate, risedronate, pamidronate, and zoledronate (Table 1). The mechanisms of action of both these categories of bisphosphonates and their potency in inhibiting osteoclasts are quite different. The non-nitrogen containing bisphosphonates, after uptake by the osteoclasts, are metabolized to hydrolysis-resistant analogs of adenosine triphosphate, resulting in apoptosis of the cells and thereby inhibiting osteolysis. The nitrogen-containing bisphosphonates inhibit the mevalonate pathway in cholesterol synthesis by inhibiting farnesyl diphosphate synthase. This property of aminobisphosphonates results in the inhibition of posttranslational lipid modification (prenylation) of certain signaling proteins that are essential for cell growth signaling.
Table I Types of bisphosphonates

\begin{tabular}{|c|c|c|}
\hline Types & $\begin{array}{l}\text { Non-nitrogenous } \\
\text { bisphosphonates }\end{array}$ & $\begin{array}{l}\text { Nitrogenous } \\
\text { bisphosphonates }\end{array}$ \\
\hline $\begin{array}{l}\text { Mechanism of } \\
\text { action }\end{array}$ & $\begin{array}{l}\text { After uptake into } \\
\text { osteoclasts, the } \\
\text { drug metabolizes to } \\
\text { hydrolysis-resistant } \\
\text { analogs of ATP and } \\
\text { leads to apoptosis }\end{array}$ & $\begin{array}{l}\text { After uptake into } \\
\text { osteoclasts, the drug } \\
\text { inhibits mevalonate } \\
\text { pathway in cholesterol } \\
\text { synthesis (important for } \\
\text { cell growth signaling) } \\
\text { thereby resulting in } \\
\text { apoptosis }\end{array}$ \\
\hline Examples & Clodronate, Etidronate & $\begin{array}{l}\text { Alendronate, risedronate, } \\
\text { pamidronate, zoledronate }\end{array}$ \\
\hline Administration & $\begin{array}{l}\text { Clodronate - po and iv } \\
\text { (not available in US) } \\
\text { Etidronate - po }\end{array}$ & $\begin{array}{l}\text { Alendronate - po } \\
\text { Risedronate - po } \\
\text { Pamidronate and } \\
\text { zoledronate - iv }\end{array}$ \\
\hline
\end{tabular}

Abbreviations: ATP, adenosine triphosphate; po, by mouth; iv, intravenous.

Ultimately, the mevalonate pathway inhibition results in the induction of osteoclast apoptosis. ${ }^{12}$

\section{Antitumor role}

Bisphosphonates are currently indicated for the treatment of osteoporosis and hypercalcemia, the prevention of skeletalrelated events in bone metastasis, and in the prevention of chemotherapy-induced bone loss (Table 2). However, several preclinical models and clinical studies have observed an antitumor effect with bisphosphonate use. Numerous in vitro models have found that bisphosphonates exhibit an antitumor effect by inducing apoptosis, decreasing cell proliferation, and by inhibiting tumor cell migration and angiogenesis (Table 3). ${ }^{13-18}$

These preclinical data led to several clinical trials of the adjuvant use of bisphosphonates in breast cancer. ${ }^{19-25}$ For instance, a study of adjuvant zoledronate use in around 3300 patients with early breast cancer found no significant survival benefit. ${ }^{20}$ However, a subgroup analysis based on menopausal status found evidence of significant heterogeneity, favoring adjuvant zoledronate use in improving overall survival in postmenopausal women. ${ }^{20}$ Another study of zoledronate, used upfront versus in a delayed manner, in 602 postmenopausal women with early breast cancer on an aromatase inhibitor found no difference in recurrence rates at 61 months of follow-up $(P=0.62) .{ }^{22}$ However, a study of zoledronate in

Table 2 Indications for bisphosphonate use

Treatment of osteoporosis

Treatment of hypercalcemia

Prevention of skeletal-related events in bone metastasis

Prevention of chemotherapy-induced bone loss 
Table 3 Possible mechanisms for the antitumor effects of bisphosphonates

Inhibit cancer cell adhesion to extracellular matrix proteins

Inhibit cancer cell proliferation and induce apoptosis

Inhibit cancer cell migration and invasion

Inhibit angiogenesis

1800 premenopausal women with early breast cancer found a significant risk reduction of $39 \%$ in the zoledronate group as compared to placebo (adjusted hazard ratio: $0.61 ; 95 \%$ confidence interval $[\mathrm{CI}]: 0.39-0.96 ; P=0.033) .{ }^{21}$ In addition, several adjuvant trials with bisphosphonates in early breast cancer are currently progressing.

\section{Observational studies of bisphosphonates in reducing the risk of breast cancer}

As a result of the observations from the above preclinical and clinical studies, investigators have tried to evaluate the role of bisphosphonates in the chemoprevention of breast cancer. Four observational studies exploring this association were identified on a review of the literature and are summarized in Table 4.

Newcomb et al conducted a case-control study which looked at the incidence of breast cancer in women who used bisphosphonates for the treatment of osteoporosis. ${ }^{26}$ Around 3000 incident cases of breast cancer and a control group were identified in the state of Wisconsin in the USA. Bisphosphonate use, known risk factors for breast cancer, and other potential confounding variables were ascertained by interview. Of note, more than $97 \%$ of the study population used aminobisphosphonates. In multivariable logistic regression analysis, the odds ratio for breast cancer in current bisphosphonate users compared with nonusers was 0.67 (95\% CI: 0.51-0.89). The authors also noted a statistically significant inverse dose-response relationship between breast cancer risk and the increasing use of oral bisphosphonates $(P=0.01)$. It should be noted that recall bias and unmeasured confounding with factors such as bone mineral density and alcohol use could have played a major role in biasing the results of this case-control study.

The second study by Rennert et al retrospectively looked into the relationship between bisphosphonate use and risk reduction of breast cancer. ${ }^{27}$ In this case-control study, 1832 patients with postmenopausal breast cancer were identified from the northern part of Israel. The investigators used an insurance database to obtain 2207 controls that were age-, clinic-, and ethnicity-matched. Data on bisphosphonate use were obtained from pharmacy records and were classified into categories based on the number of years used. Of note, more than $85 \%$ of the study population used alendronate, an oral preparation. In a multivariable analysis adjusting for significant risk factors and confounding factors such as age, fruit and vegetable consumption, family history, body mass index, hormone replacement therapy, number of pregnancies, months of breast-feeding, and age at first pregnancy, the investigators found a significant reduction in breast cancer risk of 28\% (hazard ratio: 0.72 ; $95 \% \mathrm{CI}$ : 0.57-0.90) with bisphosphonate use for more than 1 year before the diagnosis of cancer. Similar results were also found for bisphosphonate use regardless of duration (odds ratio: 0.80 ; 95\% CI: $0.65-0.99$ ). However, the authors did a subgroup analysis in study participants who used bisphosphonate for less than 1 year before diagnosis and found no significant risk reduction in breast cancer (odds ratio: 0.93; 95\% CI: 0.61-1.42).

Furthermore, note that the sample size for this analysis was only 43 patients and 46 controls. Again, similar to the previous case-control study, the Israeli study was also unable to adjust for an important confounding variable: bone mineral density. It is known that low bone mineral density or osteoporosis is associated with a decrease in breast cancer risk. ${ }^{28,29}$ Conversely, postmenopausal women with greater bone mineral density have been found to have a higher risk for breast cancer. ${ }^{30}$ In addition, low bone mineral density is also an indication for bisphosphonate use. Hence, the conclusion of the previous studies could be confounded by the potentially low bone mineral density of people in the control group (Figure 1).

Most of the data in the above two studies could be biased by recall, a problem inherent in the design of case-control studies. One option to circumvent this limitation would be to design a nested case-control study in larger prospective cohorts with baseline measurements of potential confounding factors. Unfortunately, for diseases such as cancer, assembling huge cohorts to successfully conduct a nested case-control study would be a challenging situation with considerable cost implications.

The recently published Women's Health Initiative substudy aimed to tackle this question in a nested case-control study design. ${ }^{31}$ In this study, Chlebowski et al attempted to investigate the association between oral bisphosphonate use and breast cancer incidence in postmenopausal women. The WHI cohort offered a particular advantage for investigating this association in that it had a baseline bone mineral density measure in about 10,000 of the 150,000 study population. 
Table 4 Observational studies on oral bisphosphonate use in decreasing breast cancer risk

\begin{tabular}{|c|c|c|c|}
\hline Study and location & Population & Conclusions & Comments \\
\hline Newcomb et $\mathrm{al}^{26}$ & 2936 breast cancer patients and & OR:a 0.67 (95\% Cl: & - Case-control study design. \\
\hline USA & 2975 population controls & $0.51-0.89)$ & $\begin{array}{l}\text { - Interview-based, hence, more risk for recall bias. } \\
\text { - Significant dose-response relationship was identified } \\
\text { with increasing use of the drug }(P \text {-trend }=0.01) \text {. } \\
\text { - Unable to adjust for low BMD. }\end{array}$ \\
\hline $\begin{array}{l}\text { Rennert et } \mathrm{al}^{27} \\
\text { Israel }\end{array}$ & $\begin{array}{l}\text { I } 832 \text { patients with postmenopausal } \\
\text { breast cancer and } 2207 \text { age-, clinic-, } \\
\text { ethnicity-matched controls }\end{array}$ & $\begin{array}{l}\text { OR:b } 0.80(95 \% \mathrm{Cl}: \\
0.65-0.99)\end{array}$ & $\begin{array}{l}\text { - Case-control study design } \\
\text { - Drug use was assessed from pharmacy database, hence, } \\
\text { more reliable. However, other variables are still prone } \\
\text { for recall bias. } \\
\text { - Drug use for less than I year had no association with } \\
\text { breast cancer incidence. } \\
\text { - Compliance with daily use was } 72 \% \text { and with weekly use } \\
\text { was } 88 \% \text {. } \\
\text { - Unable to adjust for low BMD. }\end{array}$ \\
\hline $\begin{array}{l}\text { Chlebowski et } \text { al }^{31} \\
\text { USA }\end{array}$ & $\begin{array}{l}\text { I54,768 participants of the Women's } \\
\text { Health Initiative cohort }\end{array}$ & $\begin{array}{l}\text { HR: }:^{c} 0.68(95 \% \mathrm{Cl}: \\
0.52-0.88)\end{array}$ & $\begin{array}{l}\text { - Nested case-control design within a cohort of } \\
\text { - Dostmenopausal women. } \\
\text { is minimized. However, drug use was ascertained by } \\
\text { questionnaire methods. } \\
\text { - Nearly } 5 \text { I } 56 \text { women were diagnosed with breast cancer } \\
\text { of whom II } 20 \text { were diagnosed with DCIS. } \\
\text { - Used a surrogate marker for BMD - 5-year hip fracture } \\
\text { risk score. There still might have been some significant } \\
\text { residual confounding with low BMD. } \\
\text { - Study found an increased risk for DCIS in drug users. }\end{array}$ \\
\hline Cardwell et $\mathrm{al}^{33}$ & 41,826 bisphosphonate users and & HR: ${ }^{d}$ 0.75; (95\% Cl: & - Nested case-control design within the General Practice \\
\hline UK & $\begin{array}{l}4 \mathrm{I}, 826 \text { age-, sex- and practice- } \\
\text { matched controls }\end{array}$ & $0.63-0.89)$ & $\begin{array}{l}\text { Research Database that includes nearly } 6 \% \text { of the UK } \\
\text { population. } \\
\text { - Most of the data were prospectively collected. However, } \\
\text { drug use was ascertained from prescriptions. } \\
\text { - Cancers were ascertained from diagnostic codes in } \\
\text { patient files and not from cancer registries. } \\
\text { - Other exposure variables such as smoking status, BMI, } \\
\text { and alcohol use were ascertained from diagnostic codes } \\
\text { and chart review - all subject to inaccuracies. } \\
\text { - An exploratory analysis was conducted to adjust for } \\
\text { confounding with low BMD. However, sample size for } \\
\text { the analysis is small, at } 25 \text { in each group. Therefore, } \\
\text { residual confounding might have influenced the results. }\end{array}$ \\
\hline
\end{tabular}

Notes: ${ }^{2}$ Adjusted for age at first birth, family history of breast cancer, body mass index, menopausal status, age at menopause, diagnosis of osteoporosis, smoking, and number of mammograms; banalysis was done for any bisphosphonate use. Similar results were obtained when analysis was done for bisphosphonate use $>I$ year. However, no statistically significant association was observed in patients with $<1$ year of bisphosphonate use. Adjusted for age, fruit and vegetable consumption, sports activity, family history of breast cancer, ethnicity, body mass index, use of calcium, hormone replacement therapy, number of pregnancies, months of breast-feeding, and age at first pregnancy; cadjusted for age, ethnicity, smoking, alcohol use, physical activity, body mass index, mammogram in last 2 years, prior hormone replacement therapy or oral contraceptive use, calcium and vitamin D levels, 5-year hip fracture risk score, and Gail breast cancer risk score; dadjusted for potential risk and confounding factors such as body mass index, smoking, alcohol use, and nonsteroidal anti-inflammatory drug or steroid use of calcium and vitamin $\mathrm{D}$, and hormone replacement therapy use. Abbreviations: OR, odds ratio; $\mathrm{Cl}$, confidence interval; BMD, bone mineral density; HR, hazard ratio; DCIS, ductal carcinoma in situ; BMI, body mass index.

In an earlier study, from within the population that had a baseline measurement of bone mineral density, it was found that high bone mineral density was associated with an increased risk for breast cancer, independent of Gail breast cancer risk score. ${ }^{29}$ Another study from the entire WHI cohort also found a predictive model of 5-year risk for hip fracture. ${ }^{32}$ However, this risk prediction model did not include bone mineral density as one of the variables. The authors were then able to investigate the correlation of 5-year hip fracture risk score and bone mineral density in about 10,000 people who had both of these variables measured at baseline. Based on their analysis, the authors found that the 5-year hip fracture risk score correlated well with hip bone mineral density. ${ }^{31}$ Therefore, the authors were able to use the risk score as a surrogate for bone mineral density in the multivariate Cox proportional hazards analysis. 


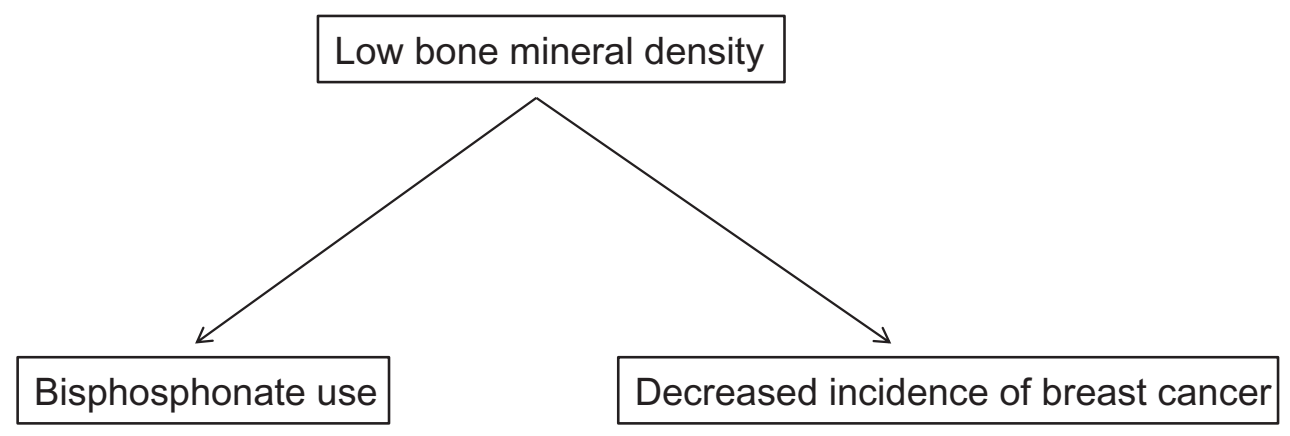

Figure I Potential confounding role of low bone mineral density in the relationship between bisphosphonate use and breast cancer incidence.

Notes: Low bone mineral density could result in bisphosphonate use. It is also known that low bone mineral density is associated with a decreased incidence of breast cancer. Therefore, the relationship between bisphosphonate use and breast cancer risk could be influenced by confounding with low bone mineral density.

The final sample size included 154,768 participants, excluding both women with a prior diagnosis of breast cancer as well as those with a history of tamoxifen or raloxifene use. Bisphosphonate use was ascertained by questionnaire at baseline and at year 3 in all participants, and additionally at year 1 in a subset of participants. It was found that around 2800 people used oral bisphosphonates at baseline. These participants had a significantly higher risk for hip fracture at 5 years based on the risk score model. It was also found that 5156 women were diagnosed with breast cancer and 1120 women were diagnosed with ductal carcinoma in situ (DCIS) after around 1.2 million person-years of observation.

The multivariate Cox proportional hazards model adjusted for age, ethnicity, smoking, alcohol use, physical activity, body mass index, mammogram in the last 2 years, prior hormone replacement therapy or oral contraceptive use, calcium and vitamin D levels, 5-year hip fracture risk score, and Gail breast cancer risk score. It was observed that oral bisphosphonate users had a $32 \%$ reduction in risk for breast cancer (hazard ratio: $0.68 ; 95 \%$ CI: $0.52-0.88 ; P<0.01$ ) after adjusting for the possible risk factors and confounding variables noted above. It was also noted that the risk for DCIS was increased in bisphosphonate users (hazard ratio: 1.58; 95\% CI: $1.08-2.31 ; P=0.02$ ).

Although this study found a significant protective role for oral bisphosphonate use in reducing the risk for breast cancer, it raised several questions. Does the 5-year hip fracture risk score adequately account for the confounding with bone mineral density? Are the findings affected by any residual confounding factors? What about the increased risk for DCIS in bisphosphonate users? Note that the increased incidence of DCIS with increasing drug exposure mirrored a pattern also observed with raloxifene use in the Breast Cancer Prevention Trial. ${ }^{6}$

The fourth study investigating the association between oral bisphosphonate use and breast cancer incidence was from the General Practice Research Database in the United Kingdom, ${ }^{33}$ which is one of the largest databases of anonymized longitudinal patient records and includes nearly $6 \%$ of the UK population. The authors put together a cohort of bisphosphonate users $(\mathrm{n}=41,826)$ and an age-, sex-, and practice-matched control population in a 1:1 matched ratio. This nested case-control study excluded participants if they had a prior history of cancer or if they had less than 6 months of follow-up.

In a Cox proportional hazard analysis, adjusting for potential risk and confounding factors such as body mass index, smoking, alcohol use, and nonsteroidal anti-inflammatory drug, steroid, use of calcium and vitamin D supplements, and hormone replacement therapy use, the study found a significant risk reduction of $25 \%$ in any users of bisphosphonates as compared to their matched controls (adjusted hazard ratio: 0.75; 95\% CI: $0.63-0.89 ; P<0.001)$. Subgroup analysis in women who used bisphosphonates for at least 1 year yielded a similar risk reduction for breast cancer, although this was not statistically significant (adjusted hazard ratio: $0.79 ; 95 \%$ CI: $0.62-1.01 ; P=0.06$ ). Further testing of a dose-response relationship in study participants who used bisphosphonates for at least 3 or 4 years found no evidence of an association.

Furthermore, in an attempt to explore confounding by low bone mineral density on breast cancer risk, the authors conducted an analysis using participants from the control population who had a diagnosis of osteoporosis or fracture and their matched bisphosphonate users. It was observed that there was no association between bisphosphonate use and breast cancer risk reduction, although the sample size was only around 25 in each group for this analysis.

\section{Conclusions}

These results showed a significant risk reduction for breast cancer with bisphosphonate use, although the presence of possible unmeasured confounding factors and the 
observational nature of these studies affected the strength of these conclusions. It should, however, be noted that these results are backed by the evidence of a biological plausibility from in vitro models. As noted from the preclinical models and clinical studies in breast cancer patients, bisphosphonates are purported to influence the tumor microenvironment in decreasing breast cancer growth and spread. Therefore, these observational studies may simply extend the benefit early into the continuum of breast cancer progression.

In conclusion, although these observational studies showed a roughly $20 \%-30 \%$ risk reduction for breast cancer with bisphosphonate use, it could only be considered hypothesis generating rather than practice changing. As described above, several confounding factors could have influenced these findings, most notably, that of low bone mineral density. Only a prospective cohort study with a baseline measurement of bone mineral density would adequately address this significant confounding factor in the relationship between bisphosphonate use and breast cancer incidence. In addition, the ideal study in this context would be a randomized controlled trial, adjusting for bone mineral density, smoking status, body mass index, alcohol use, hormone replacement therapy use, and other risk factors for breast cancer. Needless to say, given the increasing number of postmenopausal women who are placed on bisphosphonates for osteoporosis and bone protection, the association between oral bisphosphonate use and breast cancer incidence has significant public health implications and needs to be explored further.

\section{Disclosures}

The authors report no conflicts of interest in this work.

\section{References}

1. Siegel R, Naishadham D, Jemal A. Cancer statistics, 2012. CA Cancer J Clin. 2012;62(1):10-29.

2. Cuzick J, Forbes J, Edwards R, et al; for the IBIS investigators. First results from the International Breast Cancer Intervention Study (IBIS-I): a randomised prevention trial. Lancet. 2002;360(9336):817-824.

3. Fisher B, Costantino JP, Wickerham DL, et al. Tamoxifen for prevention of breast cancer: report of the National Surgical Adjuvant Breast and Bowel Project P-1 Study. J Natl Cancer Inst. 1998;90(18): 1371-1388.

4. Powles TJ, Ashley S, Tidy A, Smith IE, Dowsett M. Twenty-year follow-up of the Royal Marsden randomized, double-blinded tamoxifen breast cancer prevention trial. J Natl Cancer Inst. 2007;99(4):283-290.

5. Cummings SR, Eckert S, Krueger KA, et al. The effect of raloxifene on risk of breast cancer in postmenopausal women: results from the MORE randomized trial. Multiple Outcomes of Raloxifene Evaluation. JAMA. 1999;281(23):2189-2197.

6. Vogel VG, Costantino JP, Wickerham DL, et al; for the National Surgical Adjuvant Breast and Bowel Project. Update of the National Surgical Adjuvant Breast and Bowel Project Study of Tamoxifen and Raloxifene (STAR) P-2 Trial: Preventing breast cancer. Cancer Prev Res (Phila). 2010;3(6):696-706.
7. Vogel VG, Costantino JP, Wickerham DL, et al; for the National Surgical Adjuvant Breast and Bowel Project (NSABP). Effects of tamoxifen vs raloxifene on the risk of developing invasive breast cancer and other disease outcomes: the NSABP Study of Tamoxifen and Raloxifene (STAR) P-2 trial. JAMA. 2006;295(23):2727-2741.

8. Davidson NE, Kensler TW. "MAPping" the course of chemoprevention in breast cancer. $N$ Engl J Med. 2011;364(25):2463-2464.

9. Goss PE, Ingle JN, Ales-Martinez JE, et al; for the NCIC CTG MAP.3 Study Investigators. Exemestane for breast-cancer prevention in postmenopausal women. N Engl J Med. 2011;364(25):2381-2391.

10. Cuzick J. Aromatase inhibitors in prevention--data from the ATAC (arimidex, tamoxifen alone or in combination) trial and the design of IBIS-II (the second International Breast Cancer Intervention Study). Recent Results Cancer Res. 2003;163:96-103.

11. Tabane K, Vorobiof DA. Bone targeted therapies in early breast cancer. Curr Treat Options Oncol. 2011;12(4):412-423.

12. Russell RG, Rogers MJ. Bisphosphonates: from the laboratory to the clinic and back again. Bone. 1999;25(1):97-106.

13. van der Pluijm G, Vloedgraven $H$, van Beek E, van der Wee-Pals L, Löwik C, Papapoulos S. Bisphosphonates inhibit the adhesion of breast cancer cells to bone matrices in vitro. J Clin Invest. 1996;98(3): 698-705.

14. Fournier P, Boissier S, Filleur S, et al. Bisphosphonates inhibit angiogenesis in vitro and testosterone-stimulated vascular regrowth in the ventral prostate in castrated rats. Cancer Res. 2002;62(22): 6538-6544.

15. Wood J, Bonjean K, Ruetz S, et al. Novel antiangiogenic effects of the bisphosphonate compound zoledronic acid. J Pharmacol Exp Ther. 2002;302(3):1055-1061.

16. Boissier S, Ferreras M, Peyruchaud O, et al. Bisphosphonates inhibit breast and prostate carcinoma cell invasion, an early event in the formation of bone metastases. Cancer Res. 2000;60(11): 2949-2954.

17. Boissier S, Magnetto S, Frappart L, et al. Bisphosphonates inhibit prostate and breast carcinoma cell adhesion to unmineralized and mineralized bone extracellular matrices. Cancer Res. 1997;57(18):3890-3894.

18. Shipman CM, Rogers MJ, Apperley JF, Russell RG, Croucher PI. Bisphosphonates induce apoptosis in human myeloma cell lines: a novel anti-tumour activity. Br J Haematol. 1997;98(3):665-672.

19. Diel IJ, Solomayer EF, Costa SD, et al. Reduction in new metastases in breast cancer with adjuvant clodronate treatment. $N$ Engl J Med. 1998;339(6):357-363.

20. Coleman RE, Marshall H, Cameron D, et al. Breast-cancer adjuvant therapy with zoledronic acid. $N$ Engl J Med. 2011;365(15): 1396-1405.

21. Gnant M, Mlineritsch B, Schippinger W, et al; for the ABCSG-12 Trial Investigators. Endocrine therapy plus zoledronic acid in premenopausal breast cancer. N Engl J Med. 2009;360(7):679-691.

22. Brufsky AM, Harker WG, Beck JT, et al. Final 5-year results of Z-FAST trial: adjuvant zoledronic acid maintains bone mass in postmenopausal breast cancer patients receiving letrozole. Cancer. 2012;118(5):1192-1201.

23. Hortobagyi GN, Theriault RL, Lipton A, et al. Long-term prevention of skeletal complications of metastatic breast cancer with pamidronate. Protocol 19 Aredia Breast Cancer Study Group. J Clin Oncol. 1998;16(6):2038-2044.

24. Eidtmann H, de Boer R, Bundred N, et al. Efficacy of zoledronic acid in postmenopausal women with early breast cancer receiving adjuvant letrozole: 36-month results of the ZO-FAST Study. Ann Oncol. 2010; (11):2188-2194.

25. Saarto T, Blomqvist C, Virkkunen P, Elomaa I. Adjuvant clodronate treatment does not reduce the frequency of skeletal metastases in nodepositive breast cancer patients: 5 -year results of a randomized controlled trial. J Clin Oncol. 2001;19(1):10-17.

26. Newcomb PA, Trentham-Dietz A, Hampton JM. Bisphosphonates for osteoporosis treatment are associated with reduced breast cancer risk. Br J Cancer. 2010;102(5):799-802. 
27. Rennert G, Pinchev M, Rennert HS. Use of bisphosphonates and risk of postmenopausal breast cancer. J Clin Oncol. 2010;28(22): 3577-3581.

28. Cauley JA, Lucas FL, Kuller LH, Vogt MT, Browner WS, Cummings SR. Bone mineral density and risk of breast cancer in older women: the study of osteoporotic fractures. Study of Osteoporotic Fractures Research Group. JAMA. 1996;276(17):1404-1408.

29. Chen Z, Arendell L, Aickin M, Cauley J, Lewis CE, Chlebowski R. Hip bone density predicts breast cancer risk independently of Gail score: results from the Women's Health Initiative. Cancer. 2008;113(5):907-915.

30. Buist DS, LaCroix AZ, Barlow WE, White E, Weiss NS. Bone mineral density and breast cancer risk in postmenopausal women. $J$ Clin Epidemiol. 2001;54(4):417-422.
31. Chlebowski RT, Chen Z, Cauley JA, et al. Oral bisphosphonate use and breast cancer incidence in postmenopausal women. J Clin Oncol. 2010;28(22):3582-3590.

32. Robbins J, Aragaki AK, Kooperberg C, et al. Factors associated with 5-year risk of hip fracture in postmenopausal women. JAMA. 2007;298(20):2389-2398.

33. Cardwell CR, Abnet CC, Veal P, Hughes CM, Cantwell MM, Murray LJ. Exposure to oral bisphosphonates and risk of cancer. Int $J$ Cancer. 2010;304(6):657-663.

\section{Publish your work in this journal}

Breast Cancer: Targets and Therapy is an international, peerreviewed open access journal focusing on breast cancer research, identification of therapeutic targets and the optimal use of preventative and integrated treatment interventions to achieve improved outcomes, enhanced survival and quality of life for the cancer patient.

\section{Dovepress}

View the full aims and scopes of this journal here. The manuscript management system is completely online and includes a very quick and fair peer-review system, which is all easy to use. Visit http:// www.dovepress.com/testimonials.php to read real quotes from published authors.

Submit your manuscript here: http://www.dovepress.com/breast-cancer---targets-and-therapy-journal 